\title{
GROWTH AFTER LOSS
}

\section{Antonia Boyle}

Loss is an event that we will all face in some form or another, whether it be the loss of a life, a relationship, an animal, a home or even a tooth. This loss creates an empty space where the thing we once loved and was part of us used to exist. What becomes of this gaping space that often feels like a hole in the heart? We grow into it.

The growth that occurs after a loss can often propel us into being a better person than we were before. Growth after loss is a phenomenon I discovered during the completion of my Master of Fine Arts. I arrived at this theme through my personal journey and transformation following the loss of my mother. So much of my identity was wrapped up in my mother and her illness. After her death, I found my sense of stability in life was completely gone. This caused me to take note of the things remaining in my life that stabilise and support me, my roots.

For me, a large part of my healing came through my love of gardening, where I observed the plant life cycle of loss feeding growth, and the growth then developing and dying off, returning to the ground to feed future growth. I considered how this idea of cyclical loss and growth could be applied to the human experience of loss.

Having my hands in the dirt, literally grounding myself, I pondered the function of roots. In plants, roots not only process nutrients in the soil to nourish the plant, they also provide stability, connecting themselves firmly to the ground. This stability and nourishment is what allows the plant to grow, to blossom and then go on to reproduce and continue the cycle. So many of these ideas can be applied to our own lives. Think about your own growth - where would you be without your roots? Your support system? Would you have bloomed into who you are now? It is not only the function of roots that we can apply to our own lives, but also the life cycle of the whole plant.

I start where my encounter with this idea began - death. The losses we face are ultimately a form of death, whether literal or figurative. In the physical world, what follows after death is decay. While we think of decay as "mainly associated with things that are rotten, have a bad smell and are generally symptomatic of death,"' in nature decay plays a vital role in the cycle:

Decomposition and decay are the yin to the yang of growth, and together they form two halves of the whole that is the closed-loop cycle of natural ecosystems. Everything dies, and without the processes of decomposition and decay the world would quickly become not only overflowing with the remains of dead plants and animals, but also would experience a decline in new growth, due to a shortage of nutrients, that would be locked up and unavailable in the dead forms. ${ }^{2}$

Essentially this decay (only occurring after a loss) is what allows the new life to grow; for the cycle to continue, there must be a death.

Life and death do not exist as mere opposites, but they are entwined together, inseparable. "Within itself, life is already carrying death, which is just waiting for the door to open to it."' We are surrounded by these opposing forces at all times, the light and the dark, life and death. One cannot exist without the other; our lives are a constant balance of these opposing forces. With this in mind, the negative space that comes about through a loss (death) must be filled with the opposing force, growth (life). 
Growth is a relative term that has many expressions; in my Masters degree I applied the concept of psychological growth in a physical manner through the jewellery works I created. If we look at how most plants grow, they follow a pattern that is rather simple. A seed falls to the ground, and if the ground has enough moisture and there is enough light and the temperature is right, the seed will start to sprout. Initially, there is a single root that sprouts into the ground, anchoring the seed in its place and also allowing the seed to feed from the nutrients in the soil. Once the seed is secure in the soil and feeding from the nutrients, a shoot breaks free from the soil towards the sky. As the roots begin to spread underground, anchoring and feeding the growing plant, the shoot grows leaves, allowing the plant to photosynthesise.

"The plant develops its reproductive organs which is also known as the flowering stage. After the process of pollination is completed, the plant begins to produce fruits. These fruits contain seeds, which mature on the parent plant and fall to the ground thus starting its own life cycle."'

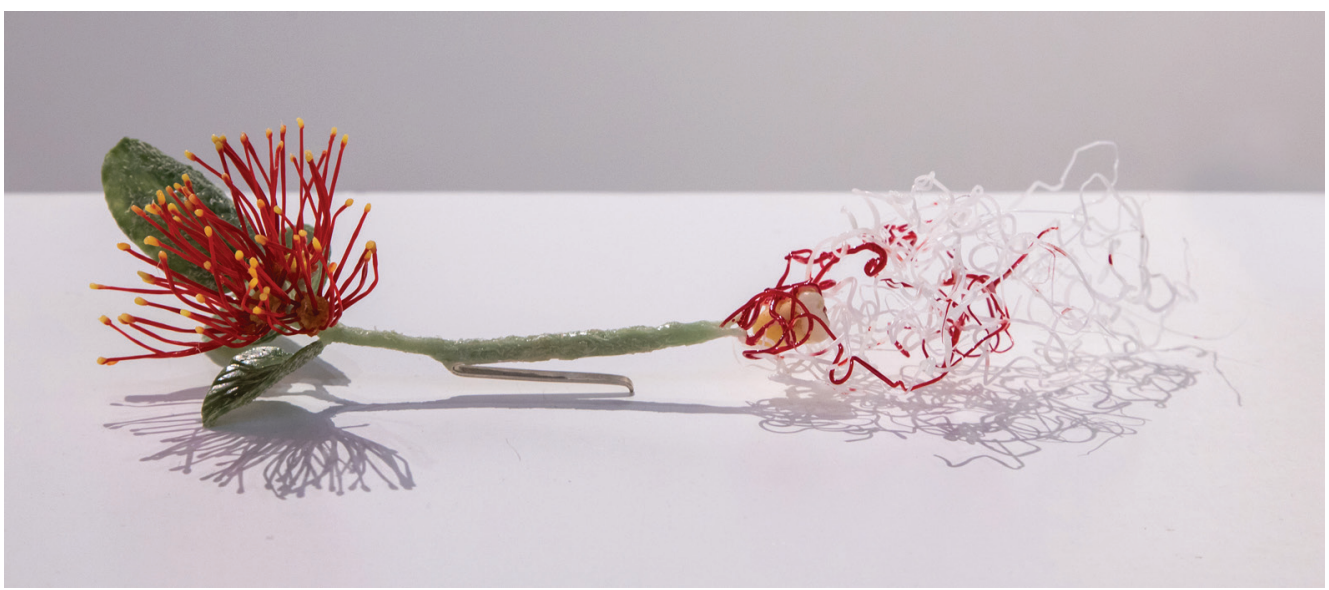

Figure I. Antonia Boyle, R.E Pohutukawa Slide, 2019, thermoplastic, human tooth, sterling silver.

Through my research I came across the term "post-traumatic growth." Post-traumatic growth (PTG) refers to "what can happen when someone who has difficulty bouncing back experiences a traumatic event that challenges his or her core beliefs, endures psychological struggle (even a mental illness such as post-traumatic stress disorder), and then ultimately finds a sense of personal growth." ${ }^{5}$

The death of my mother was a life-altering loss that challenged the way I viewed the world and myself. It is fair to say that I am person who has found certain life events difficult to deal with, especially when they triggered episodes of depression and anxiety. However, I believe that I needed to fully lose a part of myself in order to grow stronger. I feel that using my grief and experiences of life as inspiration for this project has helped me process what I have gone through in a positive way. "PTG encompasses several domains, including greater appreciation for life, development of meaningful interpersonal relationships and a greater personal strength."' | find myself looking retrospectively at how I dealt with the loss of my mother, initially retreating and then looking for help, finding myself now in a distinctly different place than I was last year (both physically and mentally). "We plant the seeds of resilience in the ways we process negative events."' I find myself growing more like a plant, reaching out under the surface, unconsciously growing my roots to ground me and growing my shoots and flowers to enjoy life after living in illness and loss for so long.

The jewellery pieces I made for my Masters embodied this theory, that death is not the end, but a space for a new beginning, for growth. My work was shown under the title "Bloom" and exhibited th the Robert Piggott Gallery, Dunedin, in February 2019. 
Each of the 12 pieces expressed the idea of loss feeding growth in physical form. The cycle begins at the point of loss, which for my work was human teeth (a loss we can all understand), in my case wisdom teeth. Surrounding the loss, appearing to grow from the tooth (or teeth, in some cases) are roots, and these roots spread across the body, seeming to grow into the wearer. The third part of the cycle is the outwards growth. In my work, growth is represented by 12 different New Zealand native flowers which appear to be sprouting forth from the point of loss, the tooth.

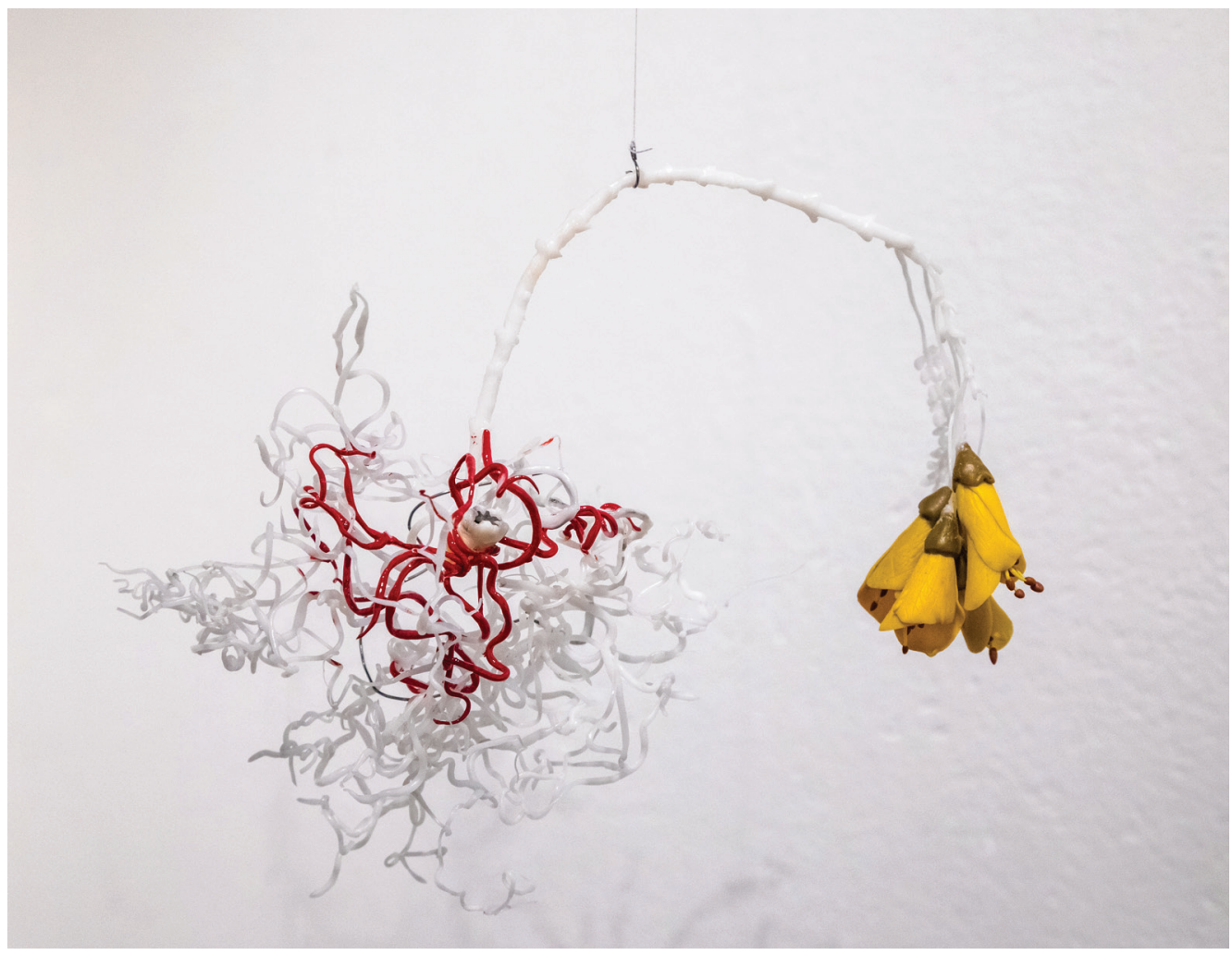

Figure 2. Antonia Boyle, H.H Kowhai Brooch, 2019, thermoplastic, polymer clay, human tooth, stainless steel.

The 12 native plants I chose to replicate in my work were taurepo, Chatham Islands forget-me-not, harakeke, kaka beak, wineberry, pohutukawa, Mount Cook buttercup, kowhai, raupeka, mānuka, houhere and poroporo. It was important to me to show both well-known natives and lesser known species, as well as a variety of sizes and colours. I wanted to express the vast diversity in our native plants. The reasons for my choosing native plants rather than introduced species, or even a mix, was to express my New Zealand identity. I was born and have lived in New Zealand my whole life and I have a strong connection to our land through its plants.

The 12 works are in various sizes and comprise brooches, slides and neck pieces. Each plant is replicated as closely as possible by my own two hands in a thermoplastic material. The size of each piece was dictated by the size of the plant in its natural form; the plants that have larger leaves thus lent themselves to being larger forms, as seen in the A.M Chatham Islands Forget-me-not Neckpiece. Smaller leafed plants with smaller flowers lent themselves to being smaller jewellery pieces, as seen in the T.E Mānuka Slide. 


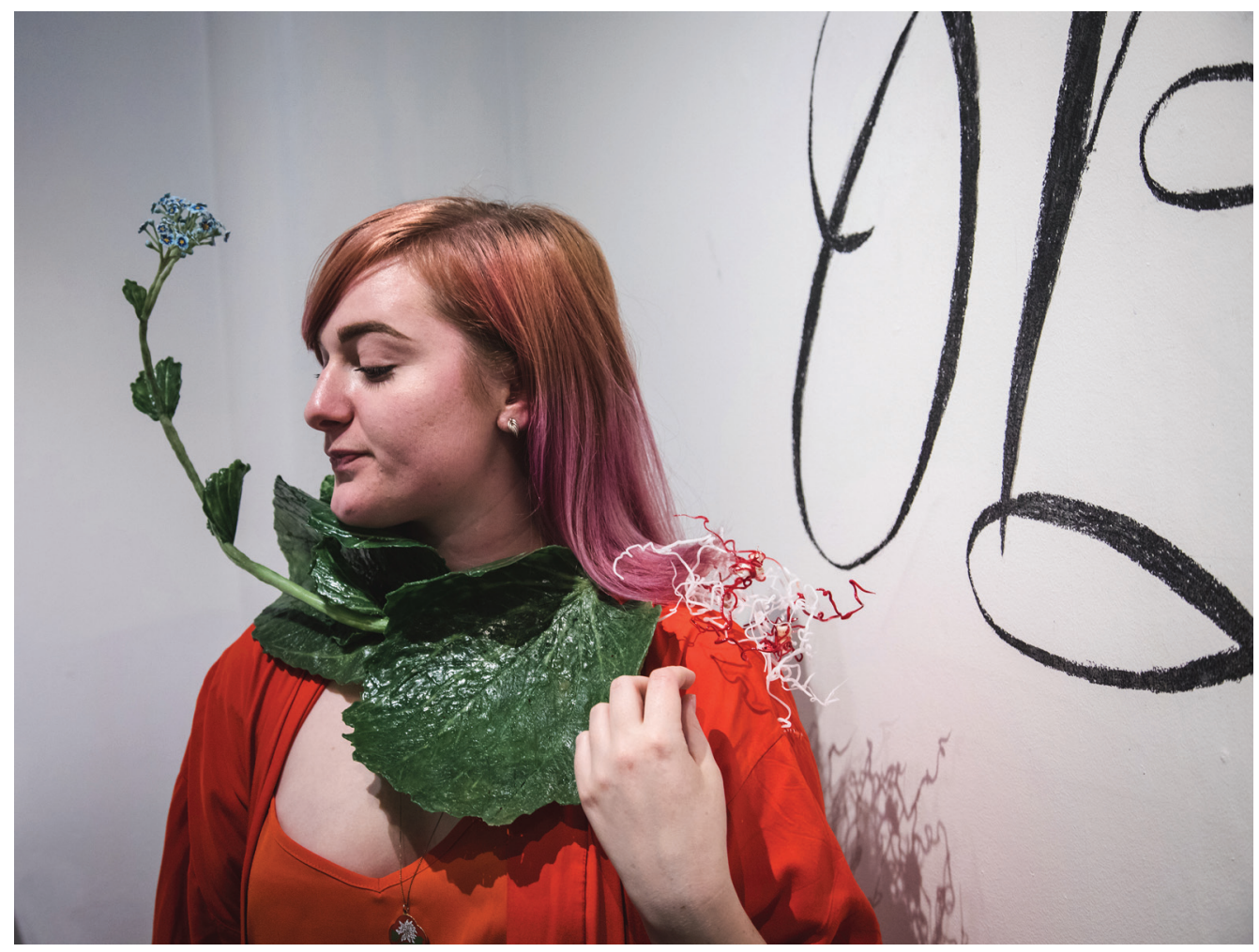

Figure 3. Antonia Boyle, A.M Chatham Islands Forget-me-not Neckpiece, 2019, thermoplastic, polymer clay, human teeth.

The pieces all sit on the chest or around the neck of the wearer. I chose to make pieces for this part of the body, as I feel it is an intimate space, close to the heart, close to our centre. When a piece is worn, it extends the space that that person occupies. In the midst of a depressed or anxious state, the sufferer wants to fade into the background and go unnoticed; however, standing tall and believing in your right to occupy space can be an empowering way of beginnng a change to a more positive lifestyle. My jewellery pieces require people to stand tall - the larger pieces make the wearer physically more present and noticeable in a positive way. This physical extension of the body portrays the unseen psychological growth that can occur after a period of loss. It can also give a sense of growth to a person who is yet to experience it, giving them insight into how it feels to stand tall and be present.

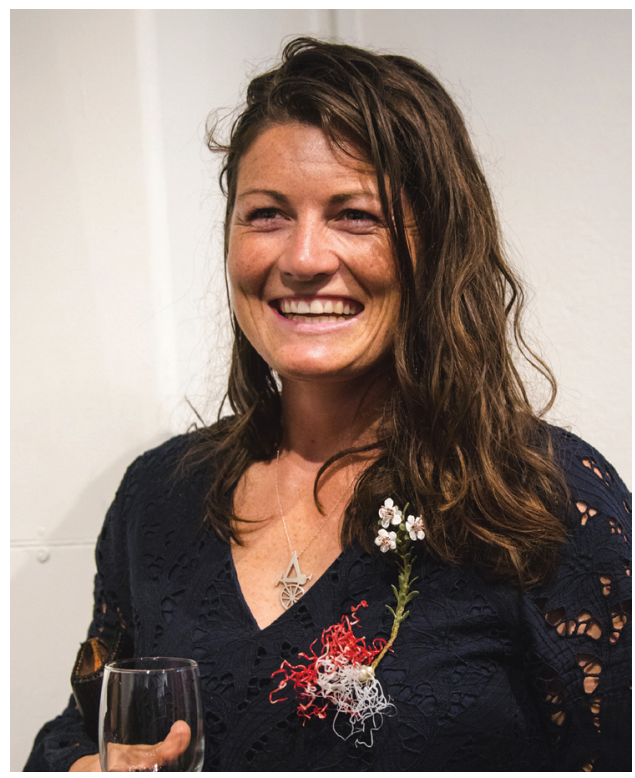

Figure 4. Antonia Boyle, T.E Mānuka Slide, 2019, thermoplastic, polymer clay, human teeth, sterling silver. 
Once worn, the wearer sees and feels how the pieces are formed around the body's curves, appearing to grow naturally around the bodies they are intended for. At the show, viewers were encouraged to try on the works and experience the sensation they produced on their body. Once they either saw other people taking the pieces down or heard that it was okay to do so, visitors became excited at the prospect of getting a closer look at the pieces and feeling them on their bodies, truly bringing them to life as they are intended to be.

Following my experience of loss and the subsequent trauma, and finally growth, l looked towards the things that gave me pleasure in life - making being one of them. The jewellery I make is made to be worn and, when this happens, it presents a different perspective to the wearer. By wearing my pieces, feeling them on your body, becoming aware of how they are blooming around the body, extending the body's occupied space, you are presented with a more positive outlook on life, growing towards the future. When you look more closely and find that this growth is centred on loss, you begin to understand the message. If this concept can speak to someone and help bring them out of the dark part of loss and introduce the idea of loss as an opportunity for a new beginning, for growth, then my work has truly fulfilled its purpose.

The contemporary jewellery exhibition "Bloom" completed Antonia Boyle's work for her Master of Fine Arts at the Dunedin School of Art. Antonia fell in love with jewellery as an art form during her studies at art school over the past seven years. Through these wearable art pieces, Antonia is able to express her passion for mental health advocacy, due to their ability to enact physical experiences in the wearers.

I Alan Watson Featherstone, "Decomposition and Decay", Trees For Life, https://treesforlife.org.uk/forest/forest-ecology/ decomposition-and-decay/ (accessed 23 July 2018)

2 Ibid.

3 Andreas Weber, Matter and Desire:An Erotic Ecology, trans. Rory Bradley (Hartford,VT: Chelsea Green Publishing, 2017 ), 55.

4 BiologyWise Staff, "An Overview of the Plant Growth Process: How Does a Plant Grow?," Biologywise, https://biologywise. com/plant-growth-process-how-does-plant-grow (accessed 9 July 2018).

5 Lorna Collier, "Growth after Trauma:Why Some People are More Resilient than Others - and Can it be Taught?," American Psychological Association: Monitor on Psychology, 47:10 (November 2016).

6 Kristen A Louiselle et al., "Posttraumatic Growth Associated with a Relative's Serious IIIness," Families, Systems \& Health, 26: I (201 I), 64-72.

7 Sheryl Sandberg and Adam Grant, Option B: Facing Adversity, Building Resilience, and Finding Joy (London:WH Allen, 2017 ), 16. 